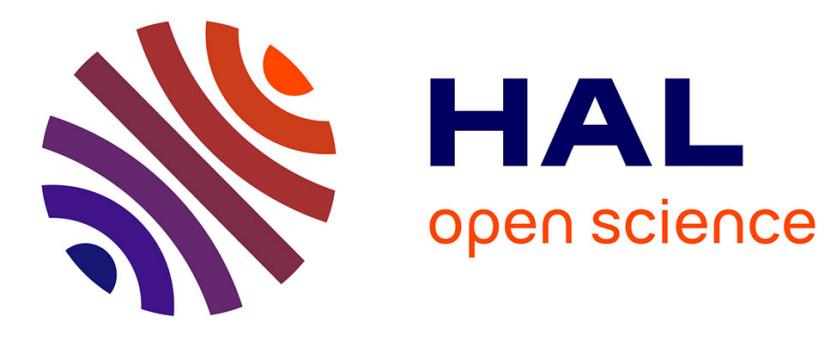

\title{
Reconfigurable antennas radiations using plasma Faraday cage
}

Oumar Alassane Barro, Mohamed Himdi, Olivier Lafond

\section{To cite this version:}

Oumar Alassane Barro, Mohamed Himdi, Olivier Lafond. Reconfigurable antennas radiations using plasma Faraday cage. International Conference on Electromagnetics in Advanced Applications (ICEAA 2015), Sep 2015, Turin, Italy. pp.545-549, 10.1109/ICEAA.2015.7297175 . hal-01298883

\section{HAL Id: hal-01298883 \\ https://hal.science/hal-01298883}

Submitted on 7 Apr 2016

HAL is a multi-disciplinary open access archive for the deposit and dissemination of scientific research documents, whether they are published or not. The documents may come from teaching and research institutions in France or abroad, or from public or private research centers.
L'archive ouverte pluridisciplinaire HAL, est destinée au dépôt et à la diffusion de documents scientifiques de niveau recherche, publiés ou non, émanant des établissements d'enseignement et de recherche français ou étrangers, des laboratoires publics ou privés. 


\title{
Reconfigurable Antennas Radiations Using Plasma Faraday Cage
}

\author{
O. A. Barro* \\ O. Lafond* \\ H. Himdi*
}

\begin{abstract}
This letter presents a new reconfigurable plasma antenna associated with a Faraday cage. The Faraday cage is realized using a fluorescent lamp. A patch antenna with a broadside radiation pattern or a monopole antenna with an end-fire radiation pattern, operating at $2.45 \mathrm{GHz}$, is placed inside Faraday cage. The performance of the reconfigurable system is observed in terms of input reflection coefficient, gain and radiation pattern via simulation and measurement. It is shown that by switching ON the fluorescent lamp, the gain of the antenna decreases. This reconfigurable antenna can be used to avoid coupling with other communications or radar systems working in the same frequency band.
\end{abstract}

\section{INTRODUCTION}

Plasma refers to the fourth state of matter. When the plasma inside a container (tube in our case) is energized (state $\mathrm{ON}$ ), the media performs like a conductive element capable to reflect radio signals like a metal [1]. But, when the tube is de-energized (State OFF), the plasma is non-conductor and electromagnetic waves can go through it. In the literature, plasma can be used as radiator to replace metallic radiator or as reflector. The main advantage of plasma reflector or plasma antenna compared to metallic element resides in the possibility to use an electrical control rather than a mechanical one. In [2], the authors proposed plasma reflector antennas in order to steer the beam in certain directions. More recently, reconfigurable reflector plasma antennas have been realized by using lowcost commercial fluorescent lamps (CFL) [3]. On the other hand, a monopole fluorescent tube antenna was proposed in $[4,5]$.

In this letter, we present reconfigurable antennas using plasma faraday cage. A Faraday cage is an enclosure formed by a conductive material or by a mesh of such material. In our case, the Faraday cage is realized by using a fluorescent lamp which allows to switch ON or OFF the plasma and to obtain reconfigurable gain and radiation patterns.

The paper is organized as follows: in section II, the patch and monopole antennas as well as the

\footnotetext{
*Institute of Electronics and Telecommunications of Rennes (IETR), UMR CNRS 6164, University of Rennes 1, 263 av. du General Leclerc, 35042 Rennes, France, e-mail: oumar-alassane.barro@univ-rennes1.fr, e-mail: olivier.lafond@univ-rennes1.fr, e-mail: mohamed.himdi@univ-rennes1.fr, tel.: +3302 23 $23 \quad 3426$
}

Faraday cage modeling and simulations are presented. The comparison between simulation and measurement results is provided in section III. A conclusion is given in section IV.

\section{MODELING AND SIMULATIONS}

First, we design two different antennas. A circular patch operating at $2.45 \mathrm{GHz}$ which radiates in broadside direction and a monopole operating also at $2.45 \mathrm{GHz}$ with end-fire radiation. The geometry of the proposed patch antenna fed by coaxial line is shown in Figure 1(a). This circular patch with a diameter of $31 \mathrm{~mm}$ is printed on an FR4 substrate with thickness $h=3.2 \mathrm{~mm}, \epsilon_{r}=4.4$ and $\tan \delta=0.025$. The diameter of the substrate is $50 \mathrm{~mm}$. The antenna is fed by a $50 \Omega$ coaxial line. The feed point is located along the $y$-axis, at a distance $d=5 \mathrm{~mm}$ from the center of the patch. The antenna is polarized along the $y$-axis and the ground plane is printed on the bottom side of the substrate.The designed quarter-wavelength monopole has a diameter of $2 \mathrm{~mm}$ and a height of $30 \mathrm{~mm}$. This monopole is placed in the center of a ground plane with a diameter of $50 \mathrm{~mm}$ (Fig. 1(b)).

Secondly, a spiral shape lamp is modelized (Fig. 1(c)) [6]. The plasma diameter is $19 \mathrm{~mm}$, the height of the lamp is $134 \mathrm{~mm}$, its inner diameter is 60 $\mathrm{mm}$, while the outer one is $98 \mathrm{~mm}$ and the gap between the coils is $3.64 \mathrm{~mm}$. A ground plane of $200 \times 200 \mathrm{~mm}^{2}$ is used in the bottom of the lamp in order to mask the electronic devices used to energize the plasma. The manufacturing prototypes and measurement setup are shown in Figure 2.

In simulation (the simulations are performed using CST Microwave studio [7]), the tubes containing the gas are made from lossy glass Pyrex with $\epsilon_{r}=4.82, \tan \delta=0.005$ and thickness of $0.5 \mathrm{~mm}$. The plasma obeys to the Drude model defined by the equation (1).

$$
\epsilon_{r}=1-\frac{\omega_{p}^{2}}{\omega(\omega-j \nu)}
$$

where $\epsilon_{r}$ is the complex plasma permittivity, $\omega_{p}$ is the plasma angular frequency, $\omega$ is the operating angular frequency and $\nu$ is the electron-neutral collision frequency.

At the beginning, we used the same Drude model 


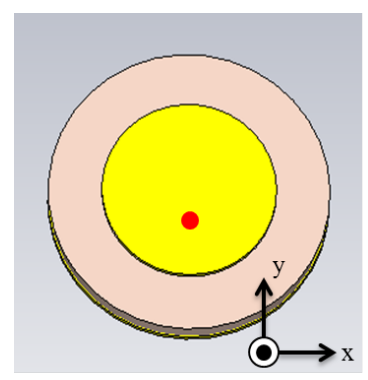

(a)

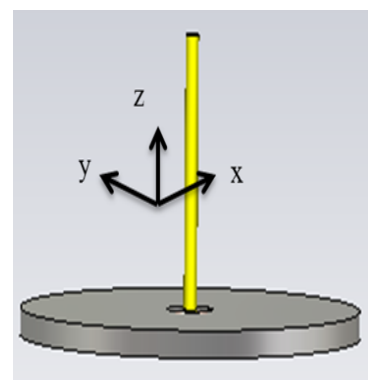

(b)

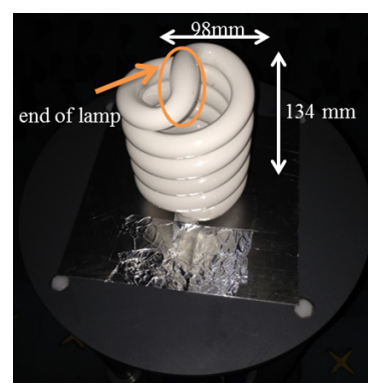

(a)

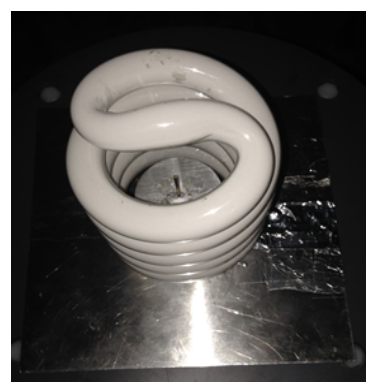

(c)

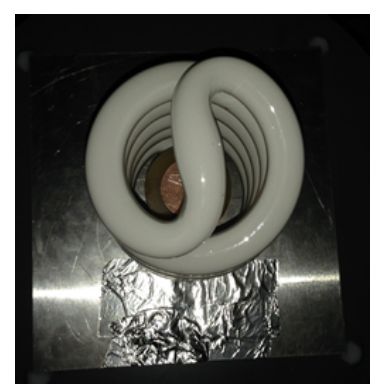

(b)

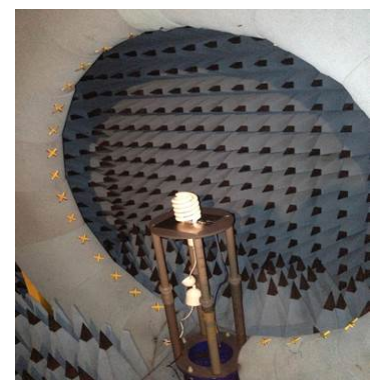

(d)

(c)

Figure 1: The designed models. (a) The patch antenna. (b) The monopole antenna. (c) The Fluorescent lamp.

as in [3], with the same parameters $(\nu=900 \mathrm{MHz}$ and $\left.\omega_{p}=43.982310^{9} \mathrm{rad} / \mathrm{s}\right)$. Unfortunately, the simulation results were not in good agreement with measurements. Hence, we tried to match the simulations with the measurement by changing the plasma parameters defined in the Drude model. After retro-simulations, $\omega_{p}=62.831810^{9} \mathrm{rad} / \mathrm{s}$ is considered and $\nu$ is kept equal to $900 \mathrm{MHz}$. In the absence of information from the manufacturer, the retro-simulation was necessary in order to have realistic plasma data for this kind of lamp.

\section{RESULTS AND DISCUSSION}

Simulated and measured $S_{11}$ parameters are shown in Figure 3 for both patch and monopole cases and by switching ON or OFF the fluorescent lamp (Plasma ON / Plasma OFF). For the patch case and all configurations (patch alone, plasma OFF, plasma $\mathrm{ON}$ ), the resonant frequency is close to 2.45 $\mathrm{GHz}$ and simulation and measurement are in good agreement (Fig. 3(a) and 3(b)). These results show that the matching of patch is not significantly affected by the plasma tube (ON or OFF). In the case of the monopole (Fig. 3(c) and 3(d)), the antenna is not well matched at the operating frequency in ON case. The plasma affects the antenna's resonance.

Figure 2: Realized model. (a) Dimensions of plasma Faraday cage. (b) Patch antenna inside the plasma Faraday cage. (c) Monopole antenna inside the plasma Faraday cage. (d) Radiation pattern measurement setup (SATIMO)

Radiation patterns have been measured in order to validate the simulation results. Measurements have been performed in a SATIMO anechoic chamber (near-fields setup) with peak gain accuracy equal to $\pm 0.8 \mathrm{dBi}$. Figure 4 shows the measured and simulated radiation patterns at $2.45 \mathrm{GHz}$. For both simulation and measurements results, each radiation pattern is normalized to the maximum value of plasma OFF. It can be observed that the radiation patterns in measurement and simulation are quite similar. For the patch antenna, in both simulation and measurement the difference of gain between plasma OFF and $\mathrm{ON}$ at $\theta=0$ (broadside) is $12 \mathrm{~dB}$ (Fig. 4(a), 4(b)). The gain of antenna is slightly decreased when the plasma is ON because the electric field polarization is parallel to the end of the lamp (Fig. 2(a)). For the monopole antenna (Fig.4(c) and 4(d)), the difference is lower, almost $5 \mathrm{~dB}$, because the electric filed polarization of monopole is orthogonal to the spiral part of the lamp. So the electromagnetic waves coming from the monopole are less attenuated.

Table 1 shows the maximum realized gain at 2.45 $\mathrm{GHz}$ for the patch and the monopole antenna cases. The simulation and measurement are in good agreement. It is interesting to note that the radiation of 


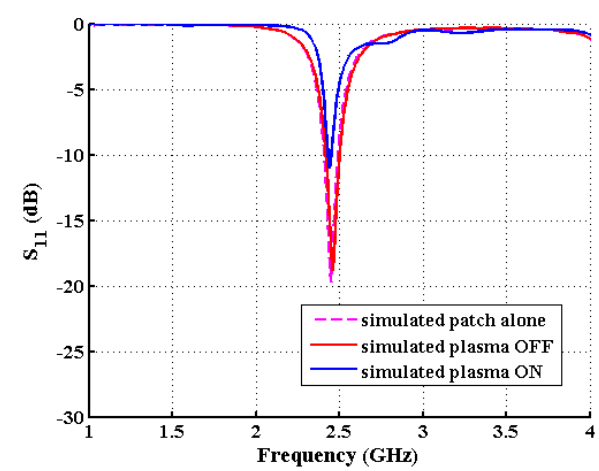

(a)

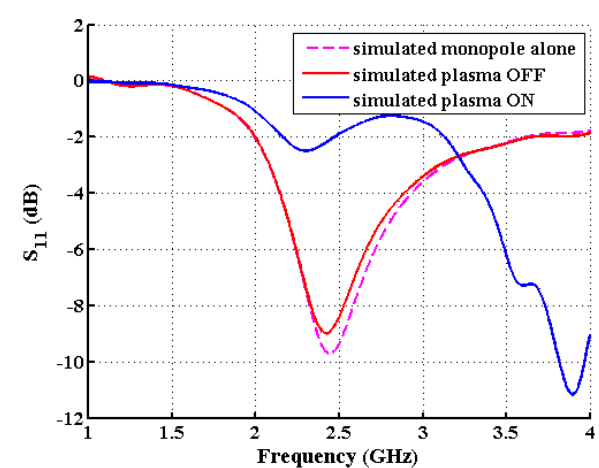

(c)

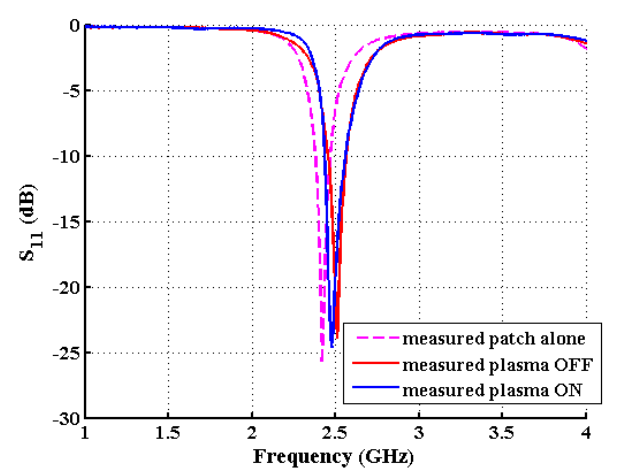

(b)

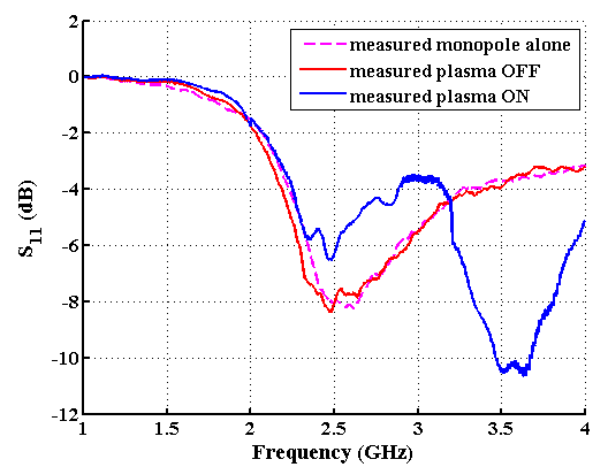

(d)

Figure 3: $S_{11}$ magnitude parameter comparison. (a) Simulated $S_{11}$ patch antenna case. (b) Measured $S_{11}$ patch antenna. (c) Simulated $S_{11}$ monopole antenna case. (d) Measured $S_{11}$ monopole antenna.

Table 1: Maximum simulated and measured gain for the patch and monopole antennas

\begin{tabular}{|c|c|c|c|c|}
\hline Configurations & \multicolumn{2}{|c|}{ Patch antenna } & \multicolumn{2}{c|}{ Patch antenna } \\
\hline & Plasma OFF & Plasma ON & Plasma OFF & Plasma ON \\
\hline Maximum simulated gain (dBi) & 6.4 & 0.3 & 3.4 & -1.3 \\
\hline Maximum measured gain (dBi) & 5.5 & -0.7 & 2.3 & 0.5 \\
\hline
\end{tabular}

the patch can be strongly reduced when the plasma is ON. This means that the lamp acts as a Faraday Cage especially in the broadside direction. This behavior can be suitable if we want to avoid coupling this antenna and other near communication systems or to protect it against external undesirable signal.

\section{CONCLUSION}

In this letter, a Faraday cage using commercial Fluorescent Lamp (plasma) was presented. Two types of antennas were considered inside the lamp to show the impact of Faraday Cage on antenna radiation pattern and polarization. By switching OFF or ON the plasma, the lamp behaves like a trans- parent media or Faraday Cage respectively. This reconfigurability could be used to reduce antenna gain when different communication systems working at the same frequency are put close to each others. The results obtained in this paper show that the plasma Faraday cage with patch antenna is more interesting than the plasma Faraday cage with monopole antenna.

\section{Acknowledgments}

The authors would like to acknowledge Laurent Cronier and Jérôme Sol from IETR for their technical support. 


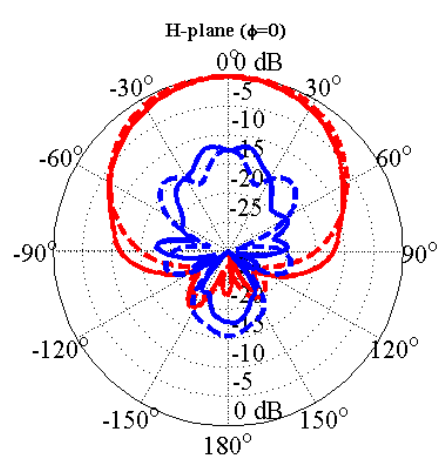

(a)

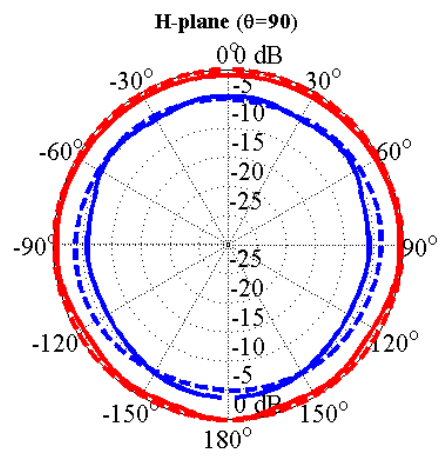

(c)

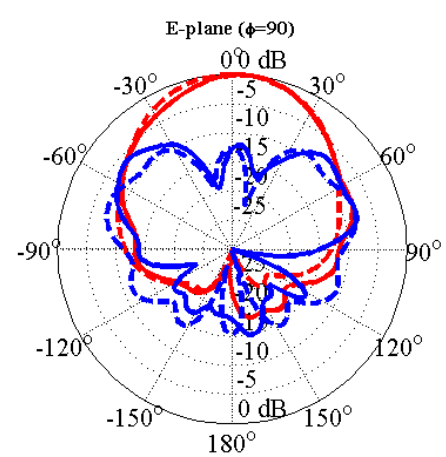

(b)

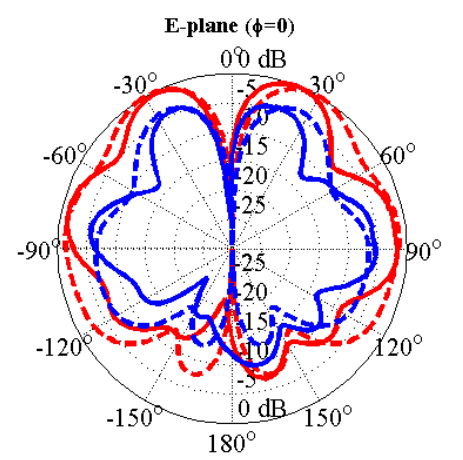

(d)

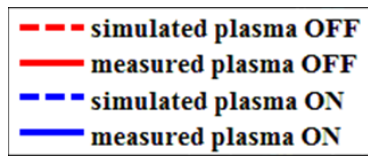

Figure 4: Normalized radiation patterns at $2.45 \mathrm{GHz}$. (a)-(b) Patch antenna case in the H-and E-planes respectively. (c)-(d) Monopole antenna case in H-and E-planes respectively.

\section{References}

[1] M. Laroussi and J.R. Roth, "Numerical calculation of the reflection, absorption, and transmission of microwaves by nonuniform plasma slab," IEEE Trans Plasma Sci., vol. 21, pp. 366-372, Aug. 1993.

[2] T. Anderson, I. Alexeff, E. Farshi, N. Karnam, E. P. Pradeep, N. R. Pulasani, J. Peck, "An operating intelligent plasma antenna," IEEE 34th International Conference on Plasma Science (ICOPS 2007), pp. 353-356, 2007.

[3] M. T. Jusoh, M. Himdi, F. Colombel, and O. Lafond, "Performance and radiation patterns of a reconfigurable plasma corner-reflector antenna," IEEE Antennas and Wireless Propagation Letters, no 99, pp. 1137-1140, 2013.
[4] Zali, H.M., Ali, M.T. ,Halili, N.A., Ja'afar, H. and Pasya, I. "Study of Monopole plasma antenna in wireless transmission applications," IEEE Transaction on Communication Technologies (ISTT), pp 52-55, Nov 2012.

[5] G. Cerri, R. De Leo, V. Mariani Primiani, and P. Russo, "Measurement of the properties of a plasma column used as a radiated element," IEEE Trans. on Instrumentation and Measurement, vol. 57, n. 2, pp. 242-247, February 2008.

[6] Maxi Helitron, 220-240V/50Hz, Beneito and Faure, Lighting S.L., http://www.beneitofaure.com/.

[7] CST, "Computer Simulation Technology," http://www.cst.com/ 